\title{
A case of Toxic Methaemoglobinemia by Dapsone Poisoning
}

\section{Sen $S^{1}{ }^{1}$ Chatterjee $A,{ }^{2}$ Gyan $\mathbf{G}^{3}$}

${ }^{1,2}$ Associate Professor, ${ }^{3} \mathrm{RMO}$ cum clinical tutor Department of Paediatrics, National Medical College

\section{ABSTRACT}

Dapsone (4,4-diaminodiphenylsulfone) is a commonly used drug for leprosy, dermatitis herpetiformis, lichen planus, other skin diseases and pneumocystis jiroveci infection in HIV patient. Dapsone poisoining is accidental in children. We report such a case who presented with severe cyanosis and respiratory distress and was treated successfully with intravenous methylene blue.

\section{CASE REPORT}

A 10 years old boy with mild mental retardation, presented with bluish discoloration over lips and fingertips and vomiting on admission. After 12 hours he developed respiratory distress, irritability, restlessness and the cyanosis increased. There was history of accidental ingestion of 10 dapsone tablets ( $25 \mathrm{mg}$ each) 12 hours prior to admission. The drug was prescribed for lichen planus for him, but he was not taking it regularly. Examination revealed central cyanosis, pallor, pulse rate of $124 / \mathrm{min}$ (regular, good volume), respiratory rate 50/min with intercostal and subcostal recession, oxygen saturation was $82 \%$ which did not improve even after $10 \mathrm{~L} / \mathrm{min}$ of oxygen. His temperature was normal and BP 110/70 mm Hg. Other systemic examinations were normal. Blood drawn for investigations was chocolate brown in color and it did not change its color even when it came in contact with air (Figure 2.). Arterial blood gas analysis was within normal limits $(\mathrm{pH} 7.41, \mathrm{PCO} 2$ 23.2, $\mathrm{PO} 2$ 84.6, $\mathrm{HCO} 3$ 20.2, BE-2.2 and $\mathrm{O} 2$ saturation $88 \%$ ). His hemoglobin was $8.5 \mathrm{~g} / \mathrm{dl}$.

Correspondence to: Dr. Sandip Sen

E-mail: drsandipsen@yahoo.com
WBC - 13,000, Platelet - 2,91,000. Blood urea 44 mg/dl. Serum Na+ 130meq/L and K+ 3.9 meq/L. Bilirubin-1.6mg/dl. AST - 86U/L, ALT - 38U/L, ALP - 626U/L. Total protein - 8gm/dl, albumin $4 \mathrm{gm} / \mathrm{dl}$. G-6PD level was normal. ECG and X-ray chest were normal. Methaemoglobin level on admission was $19 \%$. The child was started on supportive treatment with intravenous fluid, gastric lavage. After confirming normal G6PD level, i.v. methylene blue $(2 \mathrm{mg} / \mathrm{kg}$ of $1.0 \%$ solution) was given. Cyanosis and oxygen saturation improved remarkedly after methylene blue administration and his restlessness, distress also disappeared. One unit of packed RBC was given to the child. The child showed remarkable clinical improvement over the next few days and was discharged after 5 days.

\section{DISCUSSION}

Dapsone (4,4-diaminodiphenylsulfone) is commonly used in Multi Drug Treatment( MDT) for leprosy. It is also used in various skin lesions like Dermatitis Herpetiformis, Lichen planus. Pemphigoid etc. and Pneumocystis jiroveci infection in HIV patients. Dapsone is well absorbed orally, with peak levels after two to six hours. 70 
Sen S et al. A case of Toxic Methaemoglobinemia by Dapsone Poisoning.

to $80 \%$ of drug is bound to plasma proteins and its plasma half-life ranges between 21 and 30 hours but in toxic doses it may prolong upto two to four days. ${ }^{1}$ Dapsone poisoning in children is usually accidental. Methaemoglobinaemia is the characteristic feature. Clinical features are nausea, vomiting, abdominal pain, cyanosis, jaundice, intravascular haemolysis, anemia and CNS features of methaemoglobinemia (headache, dizziness, agitation, restlessness, tachycardia, hyperventilation, stupor, convulsions, coma etc.). Dapsone and its hydroxylated metabolite, T-amino-4'-hydroxaminediphenylsulphone, produces methaemoglobinaemia by oxidizing the iron in sixth coordination position of haemoglobin from its ferrous to its ferric form. ${ }^{2}$ This complex is dark brown and unable to transport oxygen with a leftward shift in oxygen dissociation curve, thus leading to a decreased tissue oxygenation with subsequent hypoxic features. ${ }^{3}$ Furthermore, haemolysis and the changes in oxygen affinity add on to the toxic symptoms produced by methaemoglobinemia alone. ${ }^{4}$ In methaemoglobinemia, patient's blood is chocolate brown colored and does not turn to bright red color when comes in contact with oxygen where as normally deoxygenated cyanosed blood changes to bright red immediately. The pulse oximetry oxygen saturation tends to be lower in spite of oxygen supplement while the oxygen tension $(\mathrm{PaO} 2)$ tends to be normal. Spectrophotometry and Blood Gas Analyzer, if calibrated can be used to estimate the methaemoglobin concentration. The clinical manifestations are directly related to concentration of methaemoglobin. Methaemoglobinemia of more than $10 \%$ produces clinical cyanosis, deep cyanosis and irritability are seen when the level is above $20 \%$, cardiorespiratory compromise is seen with levels above $40 \%$. At levels beyond $70 \%$, it causes severe cardiorespiratory failure, drowsiness, coma and eventually death. ${ }^{5}$

Besides conservative management with gastric lavage, charcoal, intravenous fluid, intravenous methylene blue is the drug of choice for the treatment of methaemoglobinemia. Methylene blue (methylthioninium chloride) is rapidly reduced to leuco-methylene blue by the enzyme NADPH-met$\mathrm{Hb}$ reductase which reduces the methaemoglobin back to haemoglobin by a cyclic reaction. ${ }^{6}$ As ascorbic acid should not be used in toxic methemoglobinemia, we did not give it to our patient. As the efficiency of methylene blue depends on adequate amounts of NADPH, care should be taken to exclude G6-PD deficiency. In G6-PD deficiency, methylene blue may aggravate methaemoglobinemia and haemolysis, ${ }^{7}$ so it should not be given. Exchange transfusion had been reported to be very effective in severe and resistant cases $^{8,9}$ but was later found to be of minor benefit, probably due to large volume of distribution of dapsone. ${ }^{10}$ In our child due to haemolysis and for better perfusion we had to give packed cell transfusion.

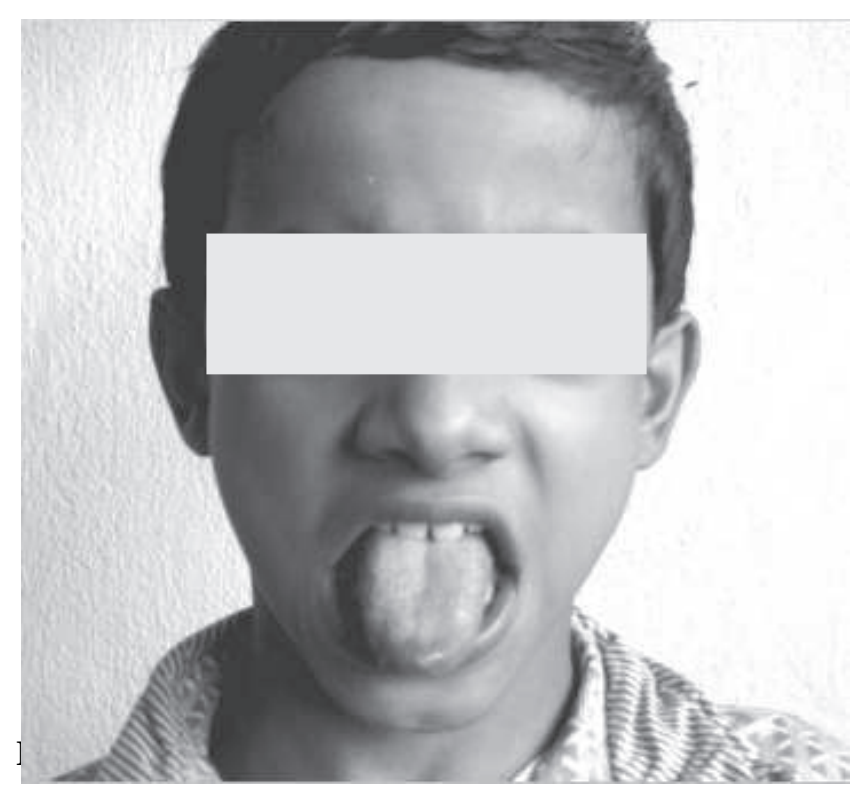




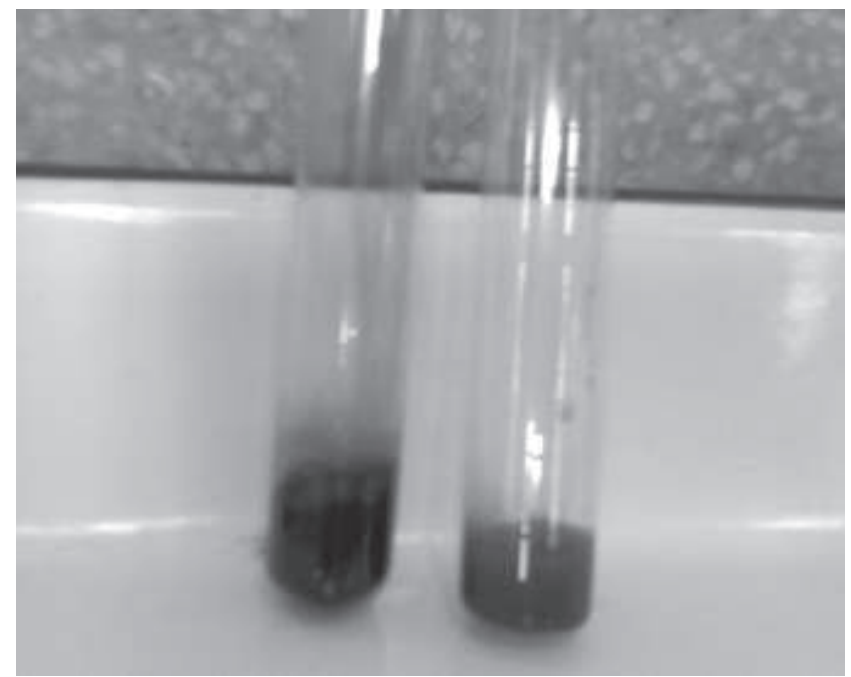

Figure 2.Blood sample of the child and normal person

\section{REFERENCES}

1. Zuidema J, Hilbers-Modderman ESM and Merkus FWHM (1986). Clinical pharmacokinetics of dapsone. Clinical Pharmacokinetics 11:299-315.

2. Kramer P, Glader B, Li T. Mechanism of methaemoglobin formation by diphenylsulphones. Biochem Pharmacol 1972; 21:1265-1274.

3. Price D. Methemoglobinemia. In: Goldfrank LR, Flomenbaum NE, Lewin NA, Weisman RS, Howland MA, Hoffman RS, editors. Goldfrank's Toxicologic emergencies, 6th ed. Stamford: Appleton \& Lange; 1998. p.1507-19.
4. Jaeger A, Sauder P, Kopferschmitt J, Flesch F (1987). Clinical features and management of poisoning due to antimalarial drugs. Medical Toxicology 2:242:273.

5. Coleman M, Coleman N. Drug-induced methaemoglobinaemia. Treatment issues. Drug Saf 1996; 14:394-405.

6. Ferguson AJ, Lavery GG. Deliberate self poisoning with dapsone: A case report and summary of relevant pharmacology and treatment. Anaesthesia 1997;52:359-63.

7. Goldstein BD. Exacerbation of dapsone induced Heinz body hemolytic anemia following treatment with methylene blue. Am J Med Sci 1974; 267:291-297.

8.Kumar A, Antony TJ, Kurein KM, Taneja LN, Mohan M, Anand NK. Exchange transfusion of dapsone poisoning. Indian Pediatr 1998;25:798-800.

9 Southgate JD, Masterson R. Lessons to be learned: a case study approach: prolonged methemoglobinaemia due toinadvertent dapsone poisoning: treatment with methylene

blue and exchange transfusion. J R Soc Health 1999; 119:52-55.

10. Berlin G, Brodin B, Hilden JO, Martensson J. Acute dapsone intoxication: A case treated with continuous infusion of methylene blue, forced diuresis and plasma exchange. J Toxicol Clin Toxicol 1984;22:537-48. 